\title{
ARTICLE
}

\section{Impact of Flow Rate in Integration with Solar Radiation on Color and COD Removal in Dye Contaminated Textile Industry Wastewater: Optimization Study}

\author{
Pradeep K. Majhi ${ }^{1}$, Rifat Azam ${ }^{1}$, Richa Kothari ${ }^{2, *}$, Naveen Kumar Arora ${ }^{1}$ and V. V. Tyagi \\ ${ }^{1}$ Department of Environmental Sciences, Babasaheb Bhimrao Ambedkar University, Lucknow, 226025, U.P., India \\ ${ }^{2}$ Department of Environmental Sciences, Central University of Jammu, Rahya-Suchani, Bagla, Samba, 181143, J\&K, India \\ ${ }^{3}$ School of Energy Management, Shri Mata Vaishno Devi University, Katra, 182320, J\&K, India \\ *Corresponding Author: Richa Kothari. Email: kothariricha21@gmail.com; richa.evs@cujammu.ac.in \\ Received: 16 April 2021 Accepted: 13 August 2021
}

\begin{abstract}
Dyes are an integral part of the dying industry and have significantly resulted in environmental pollution by altering the standard water quality after their discharge into the water bodies. The culprits behind the altered water quality are the pretreatment chemicals used during dying manufacturing processes. Various advanced treatment methods using conventional and advanced treatment options including solar energy have been put forth by researchers for the treatment of the dying effluents but, these methods have not proved significantly considerable. Therefore, the present study intends to check the efficiency of solar parabolic trough collector for treating the dying effluents in terms of color and COD. However, other wastewater parameters (BOD, nitrate and phosphate) have also been considered for this experimental analysis. Four standard flow rates $(0.5,1.3,1.95$ and $2.6 \mathrm{~L} / \mathrm{M})$ were maintained during the experiment for six hours at solar intensity $(849.3 \pm$ $\left.21.2 \mathrm{~W} / \mathrm{m}^{2}\right)$ and the optimized flow rate $(1.95 \mathrm{~L} / \mathrm{M})$ was detected and considered for further study during the present experiment. The color concentration showed a significant reduction $(\geq 76.4 \%)$ by treatment with the designed solar reactor. Similar significant results were also noticed in terms of COD $(79 \%)$. In this context, the current experimental study provides ideas on the decolorization and COD reduction efficiency with optimal flow rate in terms of cost-effectiveness with designed experimental reactor which could be further used and implemented for advanced scientific purposes.
\end{abstract}

\section{KEYWORDS}

Dye industry effluents; decolorization; renewable energy-based treatment; lab-scale experiment

\section{Introduction}

Dyes are always critical for humans as they are a part of human lifestyle and culture and have been used in an assortment of industrial sectors for the manufacturing of various textile products. These dyes are chemical compounds that adhere to surfaces or fabrics to display color and when come in contact with surface water, pose high challenges for the survival of aquatic organisms [1]. Because of their recalcitrance, dye expulsion into the hydrosphere is a major source of contamination as it gives water bodies an undesirable shade, restricts penetration of sunlight and prevents aquatic flora and fauna from photochemical and biological activities [2]. Direct discharge of dye

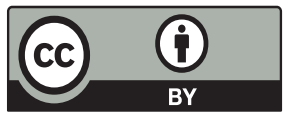

This work is licensed under a Creative Commons Attribution 4.0 International License, which permits unrestricted use, distribution, and reproduction in any medium, provided the original work is properly cited. 
effluents also results in increased alkalinity, BOD, and COD [3,4]. These alterations in the water parameters result from the pre-treatment chemicals used prior to the dyeing process. According to estimates, there are over 100,000 commercial dyes in the global sector, with an annual production of over $7 \times 10^{5}$ tonnes. The dye industry consumes more than 10,000 tonnes of dye per year, and approximately 100 tonnes of dye are dumped into water bodies every year [5,6]. These dyes need to be removed in order to bring the standard water quality. The exact treatment of these toxic dyes has not been proved efficiently. Several conventional treatment and advanced treatment options are available for this but fail in several aspects. These methods can minimize pollution from dye-contaminated textile industry wastewater, but in realistic perception, they are lacking in several sectors, like high energy requirements and more sludge generation. So, researchers are trying to find innovative and cost-effective technologies for this purpose. So, the renewable energybased treatment system is expected by the major research scientists to be accepted and, in this context, solar energy for treatment of dye contaminated textile industry wastewater is gaining attention due to its dual benefits of cost and energy-intensive in nature $[7,8]$. Solar energy is the most abundant renewable energy source, capable of degrading toxic chemical compounds and providing a cost-effective as well as renewable-based strategy with a wide range of applications scopes $[9,10]$. It is also easily accessible and could be used for a number of purposes [11]. The most widely investigated solar-powered water treatment technologies are solar desalination, solar photocatalysis, and solar disinfection [12,13]. Sharon et al. [14] briefly addressed the benefits and drawbacks of each technology, as well as the challenges of solar energy and desalination processes. Li et al. [15] conducted a very thorough study of solar-assisted seawater desalination. According to the literature, there are two forms of solar energy-based technologies: concentrated solar power (CSP) and photovoltaic (PV) technology and the parabolic trough, linear fresnel reflector systems, and central tower receiver are all part of CSP technology. For the present study, the most developed CSP technology (parabolic trough) has been preferred to be used due to its easy handling technique as well as efficiency in concentrating elevated solar radiation. The fundamental idea behind the technique is the concentration of solar radiation onto an absorptive receiver (pipe) that contains the wastewater flow. The parabolic reflecting surface concentrates the direct solar radiation on the receiver tube, creates heat, and enhances the wastewater treatment process. For the current analysis, the emphasis was held on flow rate optimization so that the impact of contact time and the effect of solar intensity on wastewater treatment could be assessed. As a result, a specific experiment focusing on the wastewater flow/circulation rate through the developed solar parabolic reactor was carried out. The wastewater molecules get contacted and influenced by solar radiation, and color and COD reduction are dependent on the way they are being influenced at the same time. The threshold limit of circulation rate plays a key role in this process. On the basis of the optimized flow rate, the present experiment was further connected. This is an innovative and renewable-based low-cost approach where concentrating solar energy-based treatment has been used for dye-contaminated textile industry wastewater treatment. To examine the efficiency of the solar parabolic trough for decolorization and COD reduction, the solar parabolic trough-reactor was built at lab-scale.

\section{Materials and Methods}

The experimental setup plan has been divided into subsections like the collection of wastewater samples and its initial characterization, designing of the solar energy-based experimental reactor, optimization of flow rate with the designed reactor, treatment of dye contaminated textile industry wastewater with optimized flow rate. 


\subsection{Collection of Wastewater Samples and Analysis}

The dye-contaminated textile industry wastewater samples were collected from Unnao (Uttar Pradesh), India (location: $26.55^{\circ} \mathrm{N} 80.49^{\circ} \mathrm{E}$ ), which is known as the industrial hub of India for textile industries and their products. The effluents were collected in 20-liter capacity plastic containers and subsequently, to avoid microbe infection and contamination, kept at $4{ }^{\circ} \mathrm{C}$. Then, the standard analytical procedures were followed (prescribed by American Public Health Association, 2012) to detect the initial physicochemical characterization.

\subsection{Fabrication of Solar Energy-Based Reactor at Lab-Scale}

The solar energy-based treatment reactor was fabricated for the color and pollution reduction of dye-contaminated textile industry wastewater. This reactor is principally based on the CPS principle where the parabolic solar collector has been designed in such a movable way so that it could manually track the solar radiation during the treatment process. Table 1 is describing the detailed specifications of the fabricated reactor.

Table 1: Specifications of solar energy-based reactor

\begin{tabular}{ll}
\hline Requirements & Measurement \\
\hline Parabolic aluminum reflective surface & Thickness: $1.5 \mathrm{~mm}$, length: 2 meter \\
Transparent glass tube & Thickness: $1.5 \mathrm{~mm}$, length: 1.5 meter \\
Wastewater tank & Capacity: 10 liter, working volume: 8 liter \\
Water holding capacity of glass tube & 4.5 liter \\
Electric motor/pump & Power rating: $0.37 \mathrm{kw} / 0.5 \mathrm{hp}$, voltage range: 180 to \\
& 240 volts \\
Plastic connector between glass pipes & Number: 2 , length: $35 \mathrm{~cm}$ \\
\hline
\end{tabular}

It consists of reflective, parabolic surface that focuses solar radiation onto the transparent glass tubes along the parabolic focal line through which the reactant fluid flows [16-18]. As a result, the collector aperture plane is always perpendicular to the solar radiation reflected by the parabola onto the reactor tube for optimum performance. The concentration factor of the solar collector is defined as the ratio between the collector's "aperture region" and "absorber area". To ensure the highest reflectivity, the trough surface was made of aluminum. The reactor tube is a closed system, so volatile compounds do not vaporize [19]. The aluminum surface was made up of $1.5 \mathrm{~mm}$ aluminum metal with two meters in length and the glass tubes are two meters in length with $1.5 \mathrm{~mm}$ thickness. Over the reflecting aluminum surface, these three connecting glass tubes have been connected in parallel forms, and connectors of hard plastic joint them so that wastewater could easily flow over the reflector. The wastewater tank is of ten liters capacity with the working volume of eight liters. Electric motor of 0.5 -hertz power has been used to flow water through the designed reactor with the plastic regulator to control wastewater flow. The whole designed reactor stands over a woody stand which is designed in such a way that it can track solar radiation manually during the experiment. The detailed schematic representation with the designed reactor given in Fig. 1. 


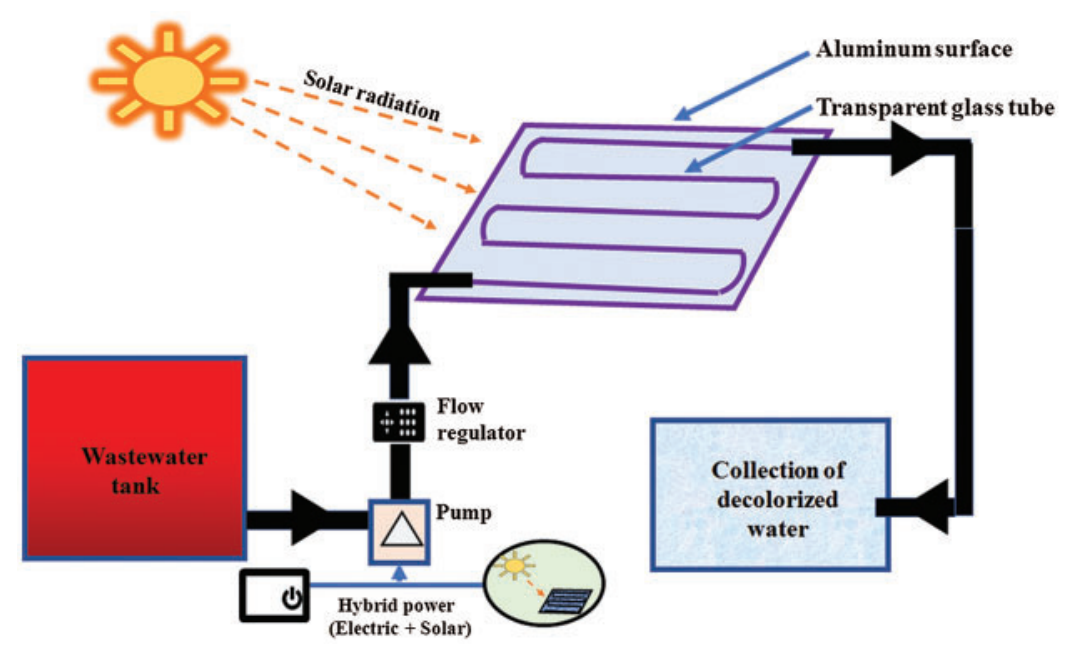

Figure 1: Sketch diagram of the designed reactor

The solar intensity was measured by solar intensity measurement device (KM-SPM-530) in $\mathrm{W} / \mathrm{m}^{2}$ on an hourly basis and the mean and standard deviation of each day was calculated in Microsoft Excel 2007. The color absorbance was checked each day by using UV spectrophotometer (HALO-DB 20) and after the experiment, the dye contaminated textile industry wastewater was collected and the COD reduction efficiency was assessed.

\subsection{Flow Rate Optimization}

The flow rate is a key influencing factor in the case of color and pollutant reduction. So, for the present study, the wastewater effluent was circulated with four different flow rates $(0.5 \mathrm{~L} / \mathrm{M}$, $1.3 \mathrm{~L} / \mathrm{M}, 1.95 \mathrm{~L} / \mathrm{M}$, and $2.6 \mathrm{~L} / \mathrm{M})$ through the designed reactor at solar radiation $(849.3 \pm 21.2$ $\mathrm{W} / \mathrm{m}^{2}$ ). The flow rate of the designed reactor was controlled by the regulator made up of hard plastic. Before confirming any standard flow rate, the primary analysis of flow rate was conducted where the experiment was run with random flow rates to gain the basic idea about the flow rates with the designed solar reactor. After conducting the preliminary study, the above-mentioned standard flow rates were maintained and run for the standard six hours of the experiment and the optimized flow rate was considered for further study of the present experiment.

\section{Results and Discussion}

The results and discussion section has been divided into three sections like characterizations of collected dye contaminated textile industry wastewater, effects of flow rate with the solar reactor, decolorization by solar radiation, and COD reduction by solar radiation. The details of the findings have been described below:

\subsection{Characterizations of Collected Dye Contaminated Textile Industry Wastewater}

The collected wastewater samples were initially analyzed by standard scientific protocol prescribed by American Public Health Association (APHA, 2012) [20]. As per the initial characterization, the dye-contaminated textile industry wastewater was highly polluted with high COD value, very bad smell, and dark blackish color with $27 \pm 0.81{ }^{\circ} \mathrm{C}$ (details have been described in Table 2). 
Table 2: The initial characteristics of collected dye contaminated textile industry wastewater

\begin{tabular}{llll}
\hline $\begin{array}{l}\text { Physico-chemical } \\
\text { parameters }\end{array}$ & Observations & $\begin{array}{l}\text { Physico-chemical } \\
\text { parameters }\end{array}$ & Observations $\left(\mathrm{mgL}^{-1}\right)$ \\
\hline Color & Dark blackish & Total solid & $5004 \pm 2.08$ \\
Temperature & $27 \pm 0.81^{\circ} \mathrm{C}$ & Total suspended solid (TSS) & $92 \pm 2.08$ \\
Order & Bad smell & Total dissolved solid (TDS) & $4904 \pm 4.5$ \\
pH & $8.2 \pm 0.1$ & Nitrate & $315 \pm 1.5$ \\
Alkalinity & $893 \pm 1.52 \mathrm{mgL}^{-1}$ & Phosphate & $3.73 \pm 0.57$ \\
Chloride & $816 \pm 0.5 \mathrm{mgL}^{-1}$ & BOD & $587 \pm 2.5$ \\
& & COD & $997.3 \pm 1.52$ \\
\hline
\end{tabular}

The initial value of COD was very high which may be due to the high nutrient load. After getting the initial characterization the flow rate was optimized for the present study. The optimized flow rate and the findings have been discussed in the upcoming section of the article.

\subsection{Effect of Solar Radiation on Color and COD Reduction}

The change in flow rate provided so many differences in the color and pollutant loads. The present study was conducted with four different flow rates $(0.65,1.3,1.95$, and $2.6 \mathrm{~L} / \mathrm{M})$ on the basis of the preliminary assessment of flow rates with the solar reactor. This experimental flow rate optimization process was processed for six hours as the prime objective of the present study was to check the best rate of circulation by which it would mostly affect the color and pollution reduction efficiency. The basic objectives behind keeping this experimental limit only for six hours were to catch the high solar intensity usually found at peak during mid-afternoon.

According to literature, when the $\mathrm{BOD}$ and $\mathrm{COD}$ ratio $(\mathrm{B} / \mathrm{C}$ ratio) is 0.5 , wastewater is quickly biodegradable, when it is $0.4-0.6$, it is average biodegradable, when it is $0.2-0.4$, it is steadily biodegradable, and when it is less than 0.2 , it is non-biodegradable [21]. The $\mathrm{B} / \mathrm{C}$ radio of the collected wastewater sample was detected at 0.5 , which is the most appropriate for wastewater degradation, so the experiment was performed with the current study using a solar-powered built reactor based on more degradability hypothesis. With varying circulation rates, substantial color and COD reduction were observed. The highest COD reduction $(10 \%)$ and decolorization $(13 \%)$ were obtained at $1.95 \mathrm{~L} / \mathrm{M}$, while the lowest COD reduction $(7 \%)$ was obtained at $0.65 \mathrm{~L} / \mathrm{M}$. COD was reduced $8.8 \%$ and $9.2 \%$ with 1.3 and $2.6 \mathrm{~L} / \mathrm{M}$, respectively. As a result, the flow rate of $1.95 \mathrm{~L} / \mathrm{M}$ was considered as the most efficient flow rate for the present experiment. The Fig. 2 is illustrating the effect of flow rates on COD reduction with specific time exposure. Although, on the basis of other used process of treatment for dye contaminated textile industry wastewater either physical, chemical, or biological the rate of decolorization and COD reduction are at large, but posses several drawbacks including use of harmful chemicals, generation of toxic byproducts, and the high-cost necessity for experimental process makes them less impactful [2,22]. So, the current experimental reactor was designed to perform up to the limit of six hours per day in the preference of sunlight to treat the dye-contaminated textile industry wastewater. 


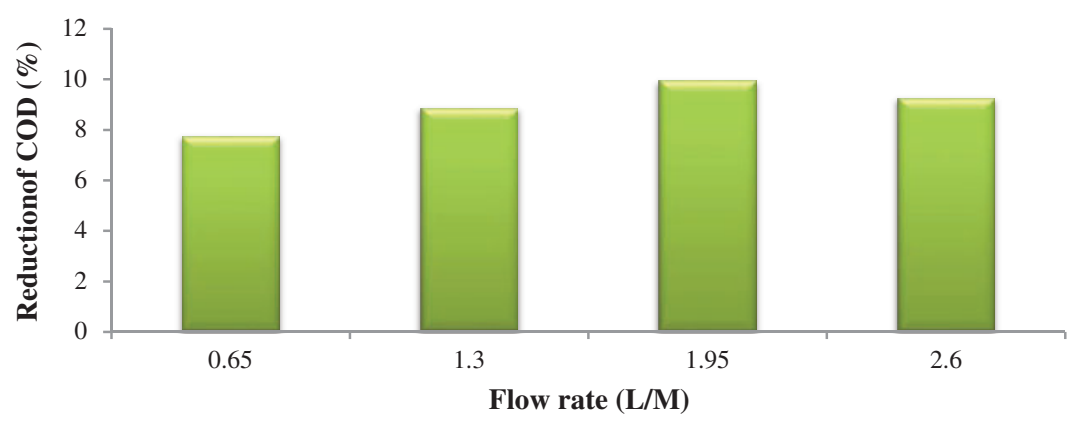

Figure 2: Effect of different flow rates on COD reduction (exposure time: six hours with solar intensity $\left(849.3 \pm 21.2 \mathrm{~W} / \mathrm{m}^{2}\right)$

The flow rate allows the wastewater molecules to move over the reflecting surface, increasing the randomness of the wastewater molecules and reducing the color concentration. However, after a certain flow rate, the contact time decreases, whether the flow rate is very high or very low. In this context, the optimum flow rate for the present designed solar reactor was $1.95 \mathrm{~L} / \mathrm{M}$ and further study was conducted with this specific flow rate during the whole experiment. Color removal from dye-contaminated textile industry wastewater was seen significantly higher by this solar energy-based treatment reactor and it was observed $\geq 76 \%$ of color concentration was reduced from the initial concentration. The high-intensity ultraviolet solar radiation is capable of breakdown the toxic chemical bonding and, at the same time, could be highly efficient for color removal from the dye-contaminated textile industry wastewater (illustrated in Fig. 3).

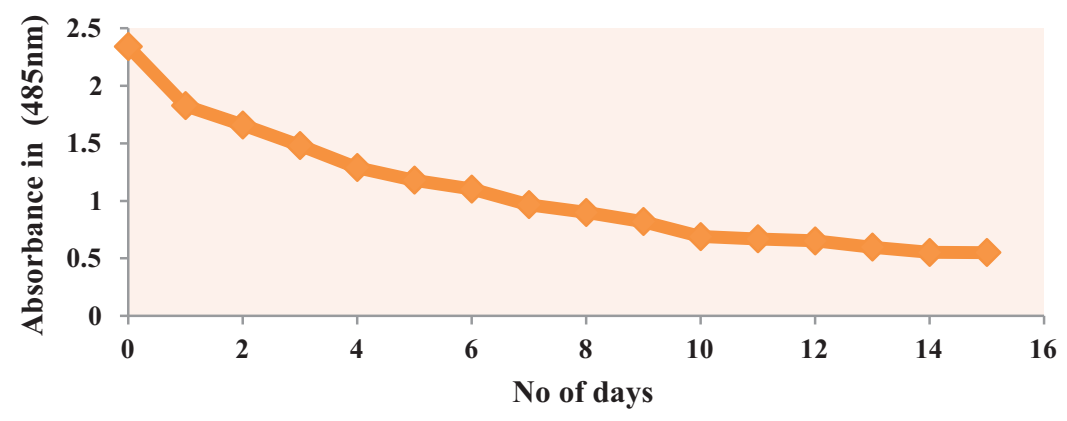

Figure 3: Effect of solar radiation on decolorization of dye contaminated textile industry wastewater with optimized flow rate $(1.95 \mathrm{~L} / \mathrm{M})$

Patil et al. [23] reported that the concentrating solar technique is one of the excellent ideas used as a superior tool for wastewater pollution minimization so that the wastewater could get high-intensity solar temperature. The high evaporation rate of wastewater causes color removal more efficiently. The high-intensity solar radiation also causes changes in the chemical oxygen demand of the effluents. The chemical oxygen demand has reduced with the working of solar treatment reactor.

The pollutant load of COD was reduced by $79 \%$ from the dye effluents, but other pollutional parameters like BOD, nitrate, and phosphate were reduced very less as compared to COD. The color concentration was reduced by $76.4 \%$ after the treatment by the solar parabolic trough reactor. Many researchers and scientists have worked on similar areas related to the present 
experimental work and also reported their findings, which are essential for this present study to be compared. Rodrigues et al. [24] reported COD removal of $30.1 \%$ to $70 \%$ while conducting experiment on optimization and economic analysis of dye contaminated textile industry wastewater under-stimulated and artificial solar radiation. Patil et al. [23] confirmed only 30\% of COD reduction while treating wastewater by parabolic trough collector. Chavaco et al. [25] reported 55\% COD reduction while evaluating the feasibility of solar pond reactors to carry out degradation of dyes. Bandala et al. [26] reported 63\% of COD removal while conducting an individual Photocatalytic decolorization technology of textile dye industry wastewater. The mechanism of solar radiation-based treatment is due to the high intensity ultraviolet radiation which is gathered by the concentrated parabolic collector. The experimental performance of decolorization during low light and without solar radiation is very less impactful as getting of ultraviolet radiation is minimum which minimizes the process efficiency. The solar intensity keeps increasing the randomness of the wastewater effluent molecules, so the color concentration drastically changes from highly dark to lightly visible at the same time, the undefined COD value also decreases with the impact of solar radiation. Also, no significant increment was noticed in the BOD of the particular dye contaminated textile industry wastewater. That is due to the highintensity solar radiation minimizes the pathogenic activities inside the dye-contaminated textile industry wastewater, so that the BOD of dye-contaminated textile industry wastewater was not so much different from the initial concentration. The same mechanism was also noticed for nutrients like nitrate and phosphate. Researchers have developed several methods for reducing color and COD in different forms of wastewater by using solar energy-based systems such as solar photovoltaic systems and solar parabolic collectors. However, the majority of them have not found to be significant with real conditions of wastewater treatment because multiple variables (temperature, $\mathrm{pH}$, reflectivity, study area location, and flow) affect the efficiency of the treatment process. The contact time is an important component in any wastewater treatment process and the efficiency of decolorization will eventually increase as the polluted wastewater molecules undergo more time in interaction with electromagnetic heat. However, after a certain period the efficiency of decolorization does not improve anymore and in this case, controlling the flow rate of the developed reactor is necessary for achieving the best performance. So, for the current study, we have optimized the flow rate of the designed solar energy-based reactor to deliver the best possible results in terms of decolorization and COD reduction which is an advanced innovative procedure that researchers and industrialists could implement in terms of decolorization and COD reduction.

\section{Conclusion}

Dye contaminated textile industry wastewater was treated by designed solar reactor with an optimized rate of circulation and noted to have remarkable decolorization and COD reduction. The pollutional parameters (BOD, nitrate, and phosphate) were also examined before and after the treatment by designed solar energy-based treatment reactor. But, more often, it was observed that there seen more enhancement in COD reduction efficiency rather than other pollutional parameters. The pathogenic growths and activities in the wastewater effluents were reduced by the highly induced ultraviolet radiation that could be the reason for less reduction of BOD, nitrate, and phosphate. This idea of solar energy-based treatment is a renewable-based treatment approach that is more efficient in terms of cost-effectiveness, generation of secondary pollutants than other conventional treatment methods. Though there are numerous treatment technologies reported by various authors for color and COD reduction from dye-contaminated textile industry wastewater, here the authors have examined the color and COD reduction with very low-cost 
expenditure. The main objective of the current study was to focus on the flow rate of the designed reactor and its impact on color and COD reduction by varying it at different rates, because it provides the relationship of contact time between wastewater molecules and solar radiation that makes the current study novel and realistic valid, while also increasing treatment efficiency. So, the research seeks to estimate cost-effectiveness, secondarily reducing waste, treatment costs, and coloration/enhancement effectiveness.

Acknowledgement: The authors acknowledge the Departmental Laboratory, Department of Environmental Sciences, and University Sophisticated Instrumentation Centre (USIC) of Babasaheb Bhimrao Ambedkar University, Lucknow (U.P.), India for providing laboratory facilities to perform the experimental work.

Funding Statement: The authors would like to thank the National Fellowship for Scheduled CasteUniversity Grant Commission, Government of India for providing financial support.

Conflicts of Interest: The authors declare that they have no conflicts of interest to report regarding the present study.

\section{References}

1. Kishor, R., Purchase, D., Saratale, G. D., Saratale, R. G., Ferreira, L. F. R. et al. (2021). Ecotoxicological and health concerns of persistent coloring pollutants of textile industry wastewater and treatment approaches for environmental safety. Journal of Environmental Chemical Engineering, 9(2), 105012. DOI 10.1016/j.jece.2020.105012.

2. Paździor, K., Bilińska, L., Ledakowicz, S. (2019). A review of the existing and emerging technologies in the combination of AOPs and biological processes in industrial textile wastewater treatment. Chemical Engineering Journal, 376(5), 120597. DOI 10.1016/j.cej.2018.12.057.

3. Majhi, P. K., Kothari, R., Arora, N. K., Pandey, V. C., Tyagi, V. V. (2021). Impact of pH on pollutional parameters of textile industry wastewater with use of Chlorella pyrenoidosa at labscale: A green approach. Bulletin of Environmental Contamination and Toxicology, 13(2), 274. DOI 10.1007/s00128-021-03208-5.

4. Sela, S. K., Nayab-U1-Hossain, A. K. M., Hussain, S. Z., Hasan, N. (2020). Utilization of prawn to reduce the value of BOD and COD of textile wastewater. Cleaner Engineering and Technology, 1(1), 100021. DOI 10.1016/j.clet.2020.100021.

5. Jegatheesan, V., Pramanik, B. K., Chen, J., Navaratna, D., Chang, C. Y. et al. (2016). Treatment of textile wastewater with membrane bioreactor: A critical review. Bioresource Technology, 204(1-4), $202-$ 212. DOI 10.1016/j.biortech.2016.01.006.

6. Yaseen, D. A., Scholz, M. (2019). Textile dye wastewater characteristics and constituents of synthetic effluents: A critical review. International Journal of Environmental Science and Technology, 16(2), 11931226. DOI 10.1007/s13762-018-2130-z.

7. Tones, A. R. M., Eyng, E., Zeferino, C. L., de Oliveira Ferreira, S., de Almeida Alves, A. A. et al. (2020). Spectral deconvolution associated to the Gaussian fit as a tool for the optimization of photovoltaic electrocoagulation applied in the treatment of textile dyes. Science of the Total Environment, 713, 136301. DOI 10.1016/j.scitotenv.2019.136301.

8. Zhai, S., Li, M., Peng, H., Wang, D., Fu, S. (2021). Cost-effective resource utilization for waste biomass: A simple preparation method of photo-thermal biochar cakes (BCs) toward dye wastewater treatment with solar energy. Environmental Research, 194, 110720. DOI 10.1016/j.envres.2021.110720.

9. Blanco, J., Malato, S., Fernández-Ibañez, P., Alarcón, D., Gernjak, W. et al. (2009). Review of feasible solar energy applications to water processes. Renewable and Sustainable Energy Reviews, 13(6-7), 1437 1445. DOI 10.1016/j.rser.2008.08.016. 
10. Tony, M. A. (2021). Solar concentration for green environmental remediation opportunity-international review: Advances, constraints and their practice in wastewater treatment. International Journal of Environmental Analytical Chemistry, 1(3), 1-33. DOI 10.1080/03067319.2021.1895138.

11. Wilberforce, T., Baroutaji, A., El Hassan, Z., Thompson, J., Soudan, B. et al. (2019). Prospects and challenges of concentrated solar photovoltaics and enhanced geothermal energy technologies. Science of the Total Environment, 659, 851-861. DOI 10.1016/j.scitotenv.2018.12.257.

12. EL-Mekkawi, D. M., Abdelwahab, N. A., Mohamed, W. A., Taha, N. A., Abdel-Mottaleb, M. S. A. (2020). Solar photocatalytic treatment of industrial wastewater utilizing recycled polymeric disposals as $\mathrm{TiO}_{2}$ supports. Journal of Cleaner Production, 249(4), 119430. DOI 10.1016/j.jclepro.2019.119430.

13. Gong, B., Yang, H., Wu, S., Tian, Y., Guo, X. et al. (2021). Multifunctional solar bamboo straw: Multiscale 3D membrane for self-sustained solar-thermal water desalination and purification and thermoelectric waste heat recovery and storage. Carbon, 171, 359-367. DOI 10.1016/j.carbon.2020.09.033.

14. Sharon, H., Reddy, K. S. (2015). A review of solar energy driven desalination technologies. Renewable and Sustainable Energy Reviews, 41(2), 1080-1118. DOI 10.1016/j.rser.2014.09.002.

15. Li, C., Goswami, Y., Stefanakos, E. (2013). Solar assisted sea water desalination: A review. Renewable and Sustainable Energy Reviews, 19(2), 136-163. DOI 10.1016/j.rser.2012.04.059.

16. Compain, P. (2012). Solar energy for water desalination. Procedia Engineering, 46, 220-227. DOI 10.1016/j.proeng.2012.09.468.

17. Kannan, N., Vakeesan, D. (2016). Solar energy for future world: A review. Renewable and Sustainable Energy Reviews, 62(1), 1092-1105. DOI 10.1016/j.rser.2016.05.022.

18. Fendrich, M. A., Quaranta, A., Orlandi, M., Bettonte, M., Miotello, A. (2019). Solar concentration for wastewaters remediation: A review of materials and technologies. Applied Sciences, 9(1), 118. DOI 10.3390/app9010118.

19. Spasiano, D., Marotta, R., Malato, S., Fernandez-Ibanez, P., di Somma, I. (2015). Solar photocatalysis: Materials, reactors, some commercial, and pre-industrialized applications. A comprehensive approach. Applied Catalysis B: Environmental, 170(13), 90-123. DOI 10.1016/j.apcatb.2014.12.050.

20. APHA (2012). Standard methods for the examination of water and wastewater. Washington DC: American Public Health Association.

21. Zhang, B., Ning, D., Yang, Y., van Nostrand, J. D., Zhou, J. et al. (2020). Biodegradability of wastewater determines microbial assembly mechanisms in full-scale wastewater treatment plants. Water Research, 169(6794), 115276. DOI 10.1016/j.watres.2019.115276.

22. Donkadokula, N. Y., Kola, A. K., Naz, I., Saroj, D. (2020). A review on advanced physico-chemical and biological textile dye wastewater treatment techniques. Reviews in Environmental Science and Bio/Technology, 19(3), 543-560. DOI 10.1007/s11157-020-09543-z.

23. Patil, L., Sachpara, S., Dixit, D. (2019). Application of solar energy in wastewater treatment. Recycled waste materials. pp. 219-223. Singapore: Springer. DOI 10.1007/978-981-13-7017-5_24.

24. Rodrigues, C. S., Madeira, L. M., Boaventura, R. A. (2013). Optimization and economic analysis of textile wastewater treatment by photo-Fenton process under artificial and simulated solar radiation. Industrial \& Engineering Chemistry Research, 52(37), 13313-13324. DOI 10.1021/ie401301h.

25. Chavaco, L. C., Arcos, C. A., Prato-Garcia, D. (2017). Decolorization of reactive dyes in solar pond reactors: Perspectives and challenges for the textile industry. Journal of Environmental Management, 198(1), 203-212. DOI 10.1016/j.jenvman.2017.04.077.

26. Bandala, E. R., Peláez, M. A., García-López, A. J., Salgado, M. D. J., Moeller, G. (2008). Photocatalytic decolourisation of synthetic and real textile wastewater containing benzidine-based azo dyes. Chemical Engineering and Processing: Process Intensification, 47(2), 169-176. DOI 10.1016/j.cep.2007.02.010. 